\title{
Masson's Tumour - Case Report of a Malignant Masquerader with Literature Review
}

\author{
Sudhakar Ramamoorthy루 Poongodi Rajagopal², Deepak Chandrasekaran³ , Vijayabasker Mithun ${ }^{4}$ \\ ${ }^{1}$ Department of Pathology, Panimalar Medical College Hospital and Research Institute, Chennai, \\ Tamilnadu, India. ${ }^{2}$ Department of Pathology, All India Institute of Medical Sciences, Mangalagiri, \\ Andhra Pradesh, India. ${ }^{3}$ Department of Surgical Oncology, Velammal Medical College Hospital and \\ Research Institute, Madurai, Tamilnadu, India. ${ }^{4}$ Department of Pathology, Velammal Medical College \\ Hospital and Research Institute, Madurai, Tamilnadu, India.
}

\section{INTRODUCTION}

Masson's tumour, an uncommon, benign vascular disorder was first described by Pierre Masson in 1923 as an intravascular papillary proliferation that emerged from an inflamed hemorrhoidal vein of a 68-year-old man and termed it as "Hemangioendotheliome vegetant intravasculaire". ${ }^{1}$ He interpreted the lesion as a form of neoplasm, however, Henschen portrayed it as a reactive phenomenon. The current terminology intravascular papillary endothelial hyperplasia (IPEH) was put forward by Clearkin and Enzinger in 1976 considering it as a reactive change occurring secondary to trauma-related vascular stasis. ${ }^{2}$ The tumour constitutes 2-4 $\%$ of all skin and soft tissue tumours. The common locations are head, neck and extremities. ${ }^{3}$ Masson's tumour being a benign entity with an excellent prognosis is essential to differentiate from its closer mimic, angiosarcoma which needs aggressive treatment. This case is put up here because of its rarity and its clinical implications.

\section{PRESENTATION OF CASE}

The patient is a 54-year-old male who came with complaints of swelling in the left elbow associated with pain for the past 6 months. On examination, a $3 \times 2.5 \mathrm{~cm}$ superficial soft tissue swelling was noted over the posterior aspect of the olecranon process. No significant epitrochlear nodes were seen. Wide local excision was planned following an incisional biopsy diagnosis of intravascular papillary endothelial hyperplasia. The patient was explained about the possible risks involved including malignancy. Excision was performed up to the deep fascia and the specimen was sent for histopathological examination.

\section{Macroscopic and Microscopic Findings}

Gross examination showed a skin covered tan red soft-tissue mass measuring $2.5 \mathrm{x}$ $1.5 \times 1.5 \mathrm{~cm}$ which on serial slicing disclosed red-brown to red-purple cystic spaces with clotted blood. Microscopic examination revealed an intravascular lesion comprising of variably dilated vascular spaces with intraluminal papillary formations with associated fibrin thrombi (Figure 1A). The papillae possessed a hyaline core and were lined by a single layer of cytologically bland cells with no evidence of atypia, multilayering or mitoses (Figure 1B). Margins were negative. Overall histopathologic findings and clinical presentation hence confirmed the incisional biopsy diagnosis of intravascular papillary endothelial hyperplasia. The absence of nuclear atypia, multilayering, mitoses or necrosis ruled out the possibility of angiosarcoma.
Corresponding Author: Dr. Poongodi Rajagopal, Assistant Professor, Department of Pathology, All India Institute of Medical Sciences, Mangalagiri, Andhra Pradesh, India. E-mail: poongodi05stanlean@gmail.com

DOI: $10.14260 /$ jemds/2021/768

How to Cite This Article:

Ramamoorthy $S, \quad$ Rajagopal $P$, Chandrasekaran D, et al. Masson's tumour - case report of a malignant masquerader with literature review. J Evolution Med Dent Sci 2021;10(44):3805-3807, DOI: 10.14260/jemds/2021/768

Submission 18-09-2021, Peer Review 29-10-2021, Acceptance 06-11-2020, Published 30-11-2021.

Copyright (C) 2021 Sudhakar Ramamoorthy et al. This is an open access article distributed under Creative Commons Attribution License [Attribution 4.0 International (CC BY 4.0)] 

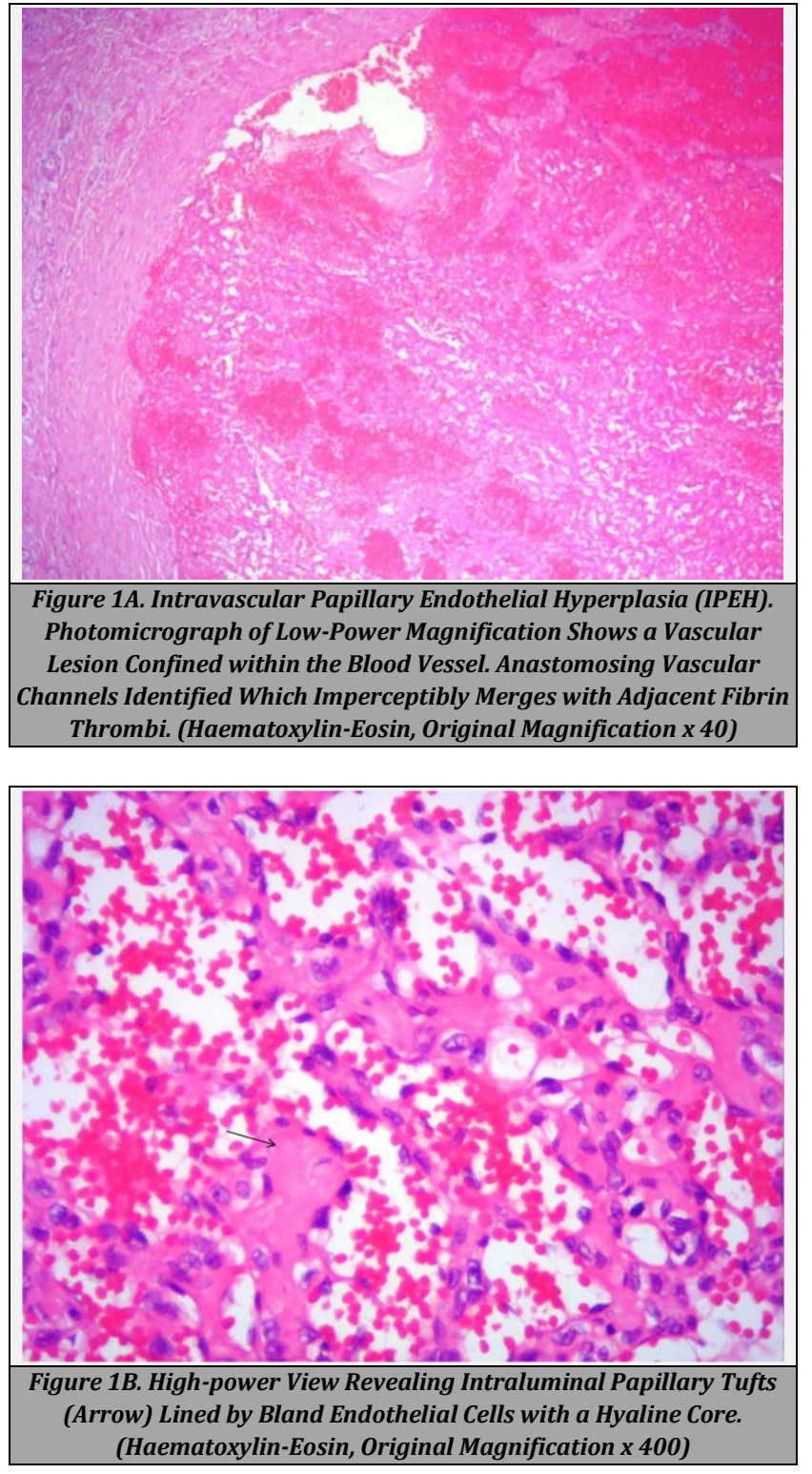

The postoperative course was uneventful. Wound healing and aesthetic results were good.

\section{DISCUSSION}

Intravascular papillary endothelial hyperplasia (Masson's tumour) is believed to be a reactive condition representing an unusual form of organizing thrombus characterized by exuberant endothelialization of thrombus fragments. ${ }^{4}$ Morphological similarities between IPEH and granulation tissues under electron microscopy might support the concept of reparative process. ${ }^{5}$

IPEH constitutes about $2 \%$ of the benign and malignant vascular tumours of the skin and subcutaneous tissues. ${ }^{6}$ Masson's tumour may occur in any blood vessel in the body, but the common sites of occurrence are fingers, head, neck and trunk. Less frequently, this tumour has also been documented in the upper respiratory tract, skeletal muscle, urogenital systems, renal, hepatic systems, and rarely in the gastrointestinal tract. The present case had shown the involvement of elbow in a 54-year-old male patient consistent with the age range reported by Buchner et al. ${ }^{7}$ (age range: $30-63$ years; mean 53 years), Tosios et al. ${ }^{8}$ (age range: 24-83 years; mean 52.3 years), however, female predilection was reported by Buchner et al. ${ }^{7}$ (1.2:1), Tosios et al. ${ }^{8}$ (3.5:1) and Makos et al. ${ }^{9}$ (1.3:1). The female predilection was attributed to hormonal influence by Irey and Norris but has not been further substantiated. ${ }^{10}$

IPEH is usually slow-growing in nature and duration varies from as less as 15 days to 6 years. ${ }^{7}$ The lesions are mostly sharply circumscribed, solitary though multiple nodules have been reported in the literature. ${ }^{9}$ In our case the patient had the swelling for 6 months and was solitary. Clinically Masson's tumours have nonspecific presentations mimicking conditions including haemangioma, traumatic fibroma, pyogenic granuloma, angiosarcoma and so on.

Radiographic studies were found to have no value in differentiating Masson's tumour from other vascular tumours. Lysyy et al. have described pure type Masson's tumour as a well-defined echogenic lesion. ${ }^{11}$ Studies have reported the use of Colour Doppler in demonstrating the hypervascular nature of the lesion. ${ }^{12}$

Masson's tumour can occur in 3 forms as pure (55.8\%), mixed (39.9\%) and extravascular (4.3\%). ${ }^{4}$ Pure form (primary) arises denovo. Mixed form occurs due to focal change in a pre-existing vascular lesion (haemangioma, pyogenic granuloma, or vascular malformation). Rarely there is extravascular location as a result of the organization of a haematoma. In the present case, no causative comorbidity or pre-existing vascular anomaly or trauma history were identified; hence it was assumed to be a pure form which is indeed the commonest.

Histologically Masson's tumour is often a welldemarcated lesion and composed of anastomosing vascular channels with intraluminal papillary tufting and are lined by a single layer of cytologically bland cells without nuclear atypia, mitosis or multilayering. The papillary core can be hyalinized and may contain thrombi or hemosiderin deposits.7,13 Necrosis usually is not a feature. Victoria blue staining can be used to highlight the expanded elastic fibres on the blood vessel. Angiosarcoma is a close histologic mimic to IPEH, however the salient features of the latter such as circumscription of a lesion, intravascular location, papillary core formation intimately associated with thrombi, lack of multilayering/mitosis /necrosis help to separate this entity from angiosarcoma. ${ }^{2,3}$ Hence microscopy is good enough for diagnosing IPEH, negating the role of immunohistochemistry. Markers like CD 31, Von Willebrand factor, CD 43, factor XIIIa can be used to highlight endothelial cells if required to prove the vascular nature of the lesion. Another marker used to differentiate IPEH from angiosarcoma is CD105 which is expressed on vascular endothelial cells and is positive in primary vascular neoplasms. ${ }^{14,15}$ In the present case, we had classic histologic findings of IPEH, hence immunohistochemistry was not done.

Treatment for IPEH is simple excision with uninvolved margins. Other modalities like using sclerosing agents followed by surgery, endoscopic surgery and the use of betaadrenergic antagonist nebivolol have also proved successful in the treatment of this lesion. 16

IPEH has an excellent prognosis if excised completely. Recurrence is more common in partially resected cases or if IPEH arises from a primary vascular lesion. In such cases, treatment should be for the primary lesion. Studies from the 
literature have shown that the lesions neither invade locally nor metastasize. ${ }^{6}$

\section{CONCLUSIONS}

IPEH is said to be a rare vascular disorder. But we presume that the incidence may rise proportional to the awareness and understanding of this entity among the medical fraternity. Moreover because of its closer resemblance to angiosarcoma on histology, imparting good knowledge (starting from clinical features, especially histology findings, till its treatment) becomes mandatory so that misdiagnosis of such a benign condition and aggressive treatment could be avoided. This case report adds to the current understanding of the nature of the lesion.

Financial or other competing interests: None.

Disclosure forms provided by the authors are available with the full text of this article at jemds.com.

\section{REFERENCES}

[1] Masson P. Hemangioendotheliome vegetant intravasculaire. Bull Soc Anat Paris 1923;93:517-23.

[2] Clearkin KP, Enzinger FM. Intravascular papillary endothelial hyperplasia. Arch Pathol Lab Med 1976;100(8):441-4.

[3] Kuo T, Sayers CP, Rosai J. Masson's "vegetant intravascular hemangioendothelioma": a lesion often mistaken for angiosarcoma: study of seventeen cases located in the skin and soft tissues. Cancer 1976;38(3):1227-36.

[4] Hashimoto H, Daimaru Y, Enjoji M. Intravascular papillary endothelial hyperplasia. A clinicopathologic study of 91 cases. Am J Dermatopathol 1983;5(6):53946.

[5] Kreutner A, Smith RM, Trefny FA. Intravascular papillary endothelial hyperplasia: light and electron microscopic observations of a case. Cancer 1978;42(5):2304-10.
[6] Amérigo J, Berry CL. Intravascular papillary endothelial hyperplasia in the skin and subcutaneous tissue. Virchows Arch A Pathol Anat Histol 1980;387(1):81-90.

[7] Buchner A, Merrell PW, Carpenter WM, et al. Oral intravascular papillary endothelial hyperplasia. J Oral Pathol Med 1990;19(9):419-22.

[8] Tosios K, Koutlas IG, Papanicolaou SI. Intravascular papillary endothelial hyperplasia of the oral soft tissues: report of 18 cases and review of the literature. J Oral Maxillofac Surg 1994;52(12):1263-8.

[9] Makos CP, Nikolaidou AJ. Intravascular papillary endothelial hyperplasia (Masson's tumor) of the oral mucosa. Presentation of two cases and review. Oral Oncol Extra 2004;40(4-5):59-62.

[10] Irey NS, Norris HJ. Intimal vascular lesions associated with female reproductive steroids. Arch Pathol 1973;96(4):227-34.

[11] Lysyy 0, Schwartz I, Kolander Y, et al. Sonographic features of intravascular papillary endothelial hyperplasia (Masson's tumor) in the forearm. J Clin Ultrasound 2011;39(5):301-3.

[12] Lee SJ, Choo HJ, Park JS, et al. Imaging findings of intravascular papillary endothelial hyperplasia presenting in extremities: correlation with pathological findings. Skeletal Radiol 2010;39(8):783-9.

[13] Soares AB, Altemani A, Furuse $C$, et al. Intravascular papillary endothelial hyperplasia: report of 2 cases and immunohistochemical study. Oral Surg Oral Med Oral Pathol Oral Radiol Endod 2008;106(5):708-11.

[14] Ohta M, Tokuda Y, Kuge S, et al. A case of angiosarcoma of the breast. Jpn J Clin Oncol 1997;27(2):91-4.

[15] Boukovalas S, Dillard R, Qiu S, et al. Intravascular papillary endothelial hyperplasia (Masson's tumor): diagnosis the plastic surgeon should be aware of. Plast Reconstr Surg Glob Open 2017;5(1):e1122.

[16] Wang ZH, Hsin CH, Chen SY, et al. Sinonasal intravascular papillary endothelial hyperplasia successfully treated by endoscopic excision: a case report and review of the literature. Auris Nasus Larynx 2009;36(3):363-6. 